\title{
Cultura de avaliação e transformação da Educação Médica: a ABEM na interlocução entre academia e governo
}

\author{
Evaluation and transformation of Medical \\ Education: ABEM mediating between \\ academy and government
}

Adriana Cavalcanti de Aguiar ${ }^{1}$ (Footnotes)

PALAVRAS-CHAVE

- Educação Médica;

- Avaliação;

- Formulação de Políticas.

\section{KEY-WORDS}

- Education, Medical;

- Evaluation;

- Policy Making;
${ }^{1}$ Associação Brasileira de Educação Médica, Universidade Estácio de Sá, Instituto de Medicina Social, Universidade do Estado do Rio de Janeiro, Rio de Janeiro, Brasil. 
da Educação. Estas "constituem orientações para a elaboração dos currículos que devem ser necessariamente adotadas por todas as instituições de ensino superior"3.

Com o fim da missão da CINAEM, passou-se ao desafio de empreender as almejadas mudanças, no contexto de aprovação e implementação das DC, processo no qual foram importantes interlocutores as escolas de medicina, organizadas em torno da ABEM e a Rede UNIDA, organização não-governamental com importante acúmulo na implantação das parcerias entre ensino-serviços e comunidade na área da saúde.

Aprovadas em 2001, as DC contém imperfeições, mas significam um importante avanço em relação à legislação prévia, que engessava a atuação das escolas mediante estabelecimento de um currículo mínimo. Destaco alguns aspectos do Parecer do Conselho Nacional de Educação (no. 1.133/2001) que institui as DC e que devem ser preservados nos processos avaliativos:

A Comissão [designada pela Câmara de Educação Superior do Conselho Nacional de Educação] reforçou nas Diretrizes Curriculares dos Cursos de Graduação em Saúde a articulação entre a Educação Superior e a Saúde, objetivando a formação geral e específica (...) com ênfase na promoção, prevenção, recuperação e reabilitação da saúde, indicando as competências comuns gerais para esse perfil de formação contemporânea dentro de referenciais nacionais e internacionais de qualidade. (...) O conceito de saúde e os princípios e diretrizes do Sistema Único de Saúde (SUS) são elementos fundamentais a serem enfatizados nessa articulação."3

O mesmo documento estabelece como Objeto das Diretrizes Curriculares,

“Permitir que os currículos propostos possam construir perfil acadêmico e profissional com competências, habilidades e conteúdos, dentro de perspectivas e abordagens contemporâneas de formação pertinentes e compatíveis com referencias nacionais e internacionais, capazes de atuar com qualidade, eficiência e resolutividade, no Sistema Único de Saúde (SUS), considerando o processo da Reforma Sanitária Brasileira."3

Com esses referenciais em mente a comunidade acadêmica vem trabalhando em inúmeras escolas para transformar currículos e processos ensino-aprendizagem-avaliação. Organizou-se também para subsidiar o processo de avaliação a ser empreendido pelo governo federal. Lideranças comprometidas com a transformação acompanharam a promulgação, em 2004 pelo Congresso Nacional, da Lei no. 10.861, de 14 de abril, que institui o Sistema Nacional de Avaliação da Educação Superior (SINAES), apresentado por seus autores como um sistema orientado para a participação ampla dos atores sociais implicados na avaliação da educação superior. Nos debates que antecederam a divulgação do SINAES representantes do governo acenaram com um posicionamento crítico ao caráter tecnocrático da avaliação então em vigor. Tal perspectiva está expressa no documento "SINAES: da Concepção à Regulamentação" ${ }^{4}$, que critica o modelo da chamada Avaliação das Condições de Ensino que antecedeu o sistema atual:

\begin{abstract}
“Os instrumentos, talvez por buscarem uma padronização da avaliação de forma um tanto exacerbada (em acordo com uma epistemologia objetivista), valorizam excessivamente dados quantitativos dos cursos, pouco possibilitando aos avaliadores agregarem suas percepções quanto à composição e pertinência do conjunto dos elementos avaliados (...). Faltam questões relativas ao corpo discente, ao entorno institucional e ao envolvimento do curso com o mesmo"4.
\end{abstract}

Delineava-se uma oportunidade de fortalecimento da participação democrática. A ABEM, articulada com outras entidades de ensino em torno do Fórum Nacional de Educação das Profissões da Saúde (FNEPAS), acompanhou o trabalho das Comissões Assessoras*, e negociou com a da medicina a busca de consenso envolvendo a comunidade acadêmica, de forma a produzir um instrumento legitimado desde sua gênese. A equipe de especialistas nomeada pelo INEP como Comissão Assessora para a elaboração do instrumento assumiu postura de cooperação identificando a ABEM como interlocutora legítima na garantia do caráter participativo propugnado pela legislação.

\section{Operacionalizando a participação em larga escala}

Ainda no XIV Fórum Nacional de Escolas Médicas ${ }^{5}$ que ocorreu no $42^{\circ}$. Congresso Brasileiro de Educação Médica, em Vitória (ES) foi possível, partindo do levantamento de instrumentos e métodos já testados $6,7,8$, avançar na construção de variáveis e indicadores que basearam, ao longo de 2005, a proposta encaminhada pela ABEM à Comissão Assessora de Medicina do INEP/MEC ${ }^{9}$.

\footnotetext{
* Conforme o art. 19., Seção II, Portaria 2051, de julho de 2004, que estabelece que os instrumentos de avaliação dos cursos de graduação terão seus conteúdos definidos com o apoio das Comissões Assessoras de Área designadas pelo INEP.
} 
Ao longo de 2005 o trabalho envolveu dezenas de escolas, organizadas em torno das respectivas Regionais da ABEM, culminando em duas Oficinas Nacionais (abril e agosto), que tiveram como subproduto o nivelamento do vocabulário e do entendimento de lideranças docentes e discentes acerca das premissas de processos de avaliação educacional. Ao convidar as escolas a participarem da primeira I Oficina Nacional sobre Avaliação das Condições de Ensino, que contou com 187 participantes a ABEM argumentava:

Aproximarmo-nos da temática da avaliação demanda articular elementos de metodologia de pesquisa, considerando também questões éticas e políticas. Avaliar implica discutir mérito e valor, e a tarefa que a ABEM propõe para o Fórum requer o estabelecimento de pactos sobre missão e estratégias. A contribuição deste debate ocorrerá na medida em que os atores envolvidos fomentem uma apropriação ampla e formativa dos mecanismos utilizados e dos resultados obtidos, num processo de educação permanente da comunidade acadêmica e seus parceiros institucionais ${ }^{10}$.

Tanto a primeira quanto a segunda oficinas nacionais incluíram apresentações de representante do INEP e do Ministério da Saúde, num esforço de articulação intersetorial. O trabalho partiu da priorização de sete macro-variáveis, tendo como base as diretrizes propostas pela Comissão Assessora e aprovadas pelo INEP11:

- Construção coletiva do projeto pedagógico

- Processos que avancem na construção do conhecimento pelo discente

- Mecanismos institucionais de fomento à transformação do papel docente

- Integração ensino-pesquisa-extensão/assistência e identificação das necessidades de saúde

- Interdisciplinaridade

- Utilização de diferentes cenários de ensino e aprendizagem

- Avaliação de competência, habilidades e conteúdos

As variáveis produzidas foram sistematizadas por um grupo designado pela Diretoria da $\mathrm{ABEM}^{12}$ e enviadas para as escolas que, organizadas em torno das respectivas regionais, discutiram como estas deveriam traduzir-se em indicadores. A II Oficina Nacional ocorreu em agosto, contando 112 participantes, demonstrando agilidade e alto nível de compromisso, e culminando na formulação de proposta coerente em tempo hábil, salientando a dificuldade de cumprir os prazos exíguos estabelecidos pelo governo.
Em maio de 2006 o INEP finalmente divulgou o documento que orientará as comissões de avaliadores de cursos ${ }^{1}$. Sua estrutura é bastante semelhante ao instrumento anterior. Causou perplexidade o fato do mesmo ser único para todas as áreas do conhecimento, desconsiderando as especificidades da área da saúde. A responsabilidade social das escolas de medicina através do desenvolvimento de parcerias institucionais e projetos de integração entre ensino-pesquisa-extensão não foi contemplada. O documento privilegia a coerência dos projetos pedagógicos e currículos com os projetos institucionais das Universidades, sendo pouco enfático na determinação de garantir coerência dos programas com as Diretrizes Curriculares.

Em recentes reuniões durante o VII Congresso da Rede Unida (Curitiba, julho de 2006), a diretoria da ABEM e o FNEPAS decidiram manter a mobilização e interlocução com os Ministérios de Educação e de Saúde, até que seja possível construir uma estratégia de fortalecimento das DC da área da saúde, garantindo sua implementação em território nacional.

\section{CONSIDERAÇÕES FINAIS}

As premissas que informam esse artigo incluem:

1)O estágio da Reforma Sanitária no qual nos encontramos aponta inequivocamente para a necessidade de mudanças no perfil de recursos humanos, o que significa transformar as graduações e fortalecer iniciativas de educação permanente em saúde. Nestas, os processos avaliativos são fundamentais.

2) Fomentar uma cultura de avaliação da educação superior depende do engajamento crescente de diferentes atores sociais. O momento histórico atual, de implantação das DC e do SINAES demanda papel ativo da comunidade acadêmica na defesa dos interesses da sociedade numa universidade comprometida com suas necessidades.

3) Os processos avaliativos podem significar fortalecimento da coesão das escolas ou de afastamento do debate, a depender da capacitação de lideranças para sua apropriação. É inadiável avançar na capacitação de lideranças da área de saúde para a avaliação educacional enfrentando o desafio da interdisciplinaridade

4) A ABEM vem desempenhando papel estratégico pela sua articulação entre docentes e discentes, e junto ao Fórum Nacional de Educação das Profissões da Área da Saúde, que vem se fortalecendo.

5) Se por um lado o incentivo do SINAES à avaliação institucional e auto-avaliação pode ser lido como um avanço, o destaque dos cursos separadamente não pode 
prescindir de garantir compromissos setoriais, como no caso da saúde.

Embora frustradas pelo encaminhamento dado pelo governo na versão final do documento de avaliação de cursos, lideranças da educação médica, organizadas em torno da ABEM e do FNEPAS deverão debater o significado político e acadêmico da situação atual. As DC continuam atuando como norte para a transformação dos cursos e existe uma importante articulação entre lideranças docentes e discentes para impedir que caiam no esquecimento. Uma estratégia viável seria a participação do FNEPAS no treinamento dos avaliadores designados pelo INEP de modo a formular conjuntamente uma interpretação do instrumento de avaliação coerente com as especificidades da área da saúde.

Além disso, a ABEM vem investindo no fomento à capacidade de auto-avaliação das escolas, aprofundando o debate e a divulgação do conhecimento sobre avaliação de habilidades e competências, e acompanhando o movimento de transformação dos cursos, através de projetos de pesquisa e da circulação de informações através da rede de Apoio à Educação Médica (RAEM). Estas iniciativas em curso fogem ao escopo desse trabalho, mas compõem, junto com o processo aqui descrito, evidências do fortalecimento da comunidade acadêmica de medicina e de sua entidade representativa.

\section{REFERÊNCIAS}

1. Brasil. Ministério da Educação. Comissão Nacional de Avaliação da Educação Superior e Instituto Nacional de Estudos e Pesquisas Educacional Anísio Teixeira. Avaliação de Cursos de Graduação - Instrumento 2006. Brasília (DF): Ministério da Educação; 2006.

2. Brasil. Leis, Decretos. Ldb: lei de diretrizes e bases da educação nacional: lei n. 9.394, de 1996. [homepage na internet]. Disponível em: http://www.camara.gov.br/internet/ infdoc/Publicacoes/html/pdf/ldb3d.pdf

3. Brasil. Ministério da Educação. Conselho Nacional de Educação. Diretrizes Curriculares Nacionais do Curso de Graduação em Medicina. [2001]. Disponível em: http:// portal.mec.gov.br/cne/arquivos/pdf/CES04.pdf

4. Brasil. Ministério da Educação. Instituto Nacional de Estudos e Pesquisas Educacional Anísio Teixeira. SINAES: da Concepção à Implementação. 2 ed. Brasília (DF): MEC; 2004.

5. Associação Brasileira de Educação Médica [homepage na internet]. XIV Fórum de avaliação da educação Médica: Documento Base para discussão. $42^{\circ}$. Congresso Brasileiro de Educação Médica. Vitória, ES, 20-24 nov. 2004. Disponível em: http://www.abem-educmed.org.br/sinaes / documento_base.pdf
6. Lampert JB. Tendências de Mudança na Formação Médica no Brasil: tipologia das escolas. São Paulo, Rio de Janeiro: HUCITEC, ABEM; 2002.

7. Ribeiro EC. Entre a emancipação e a regulação: limites e possibilidades da Avaliação das escolas médicas. 2001 [Projeto de Tese de doutorado], Instituto de Medicina Social, Universidade do Estado do Rio de Janeiro, 2001.

8. Universidade Estadual de Londrina. [homepage na internet]. Sistema Integrado de Avaliação do Curso de Medicina da Universidade Estadual de Londrina. Disponível em: http:/ /www.uel.br

9. Comissão Assessora de medicina. Proposta de Instrumento de Avaliação de Cursos de Medicina. [S.1.:S.n.]; 2005a. (mimeo.)

10. Associação Brasileira de Educação Médica [homepage na internet]. Rio de Janeiro: ABEM; 2005a. I Oficina Nacional sobre Avaliação das Condições de Ensino: Documento Base para discussão. [Abril de 2005b]. Disponível em: http:/ / w w w . a b e m-e d u c m ed.org.br/s in a e s / material_oficina_brasilia1.pdf

11. Comissão Assessora de Medicina. Diretrizes ACE Medicina. [S.1.:S.n.]; 2005c. [Documento encaminhado ao INEP]. (mimeo.).

12. Associação Brasileira de Educação Médica [homepage na internet]. Rio de Janeiro: ABEM; 2005b. Sistematização dos Relatórios dos Grupos da II Oficina Nacional sobre Avaliação das Condições de Ensino. [Maio de 2005d]. Disponível em: http://www.abem-educmed.org.br/sinaes / sistematizacao_forum_ace.pdf

13. Aguiar AC. Estratégias de Avaliação e a Transformação da Educação Médica no Brasil. Boletim ABEM. 2004; 27 (5).

\section{Endereço para correspondência}

\author{
Av. Brasil, 4036/1006 \\ 21040-361 - Manguinhos \\ Rio de Janeiro \\ E-mail: adriana.aguiar@estacio.br
}

